\title{
On the quasi-periodic nature of magnetopause flux transfer events
}

Article

Published Version

Lockwood, M. and Wild, M. N. (1993) On the quasi-periodic nature of magnetopause flux transfer events. Journal of Geophysical Research, 98 (A4). pp. 5935-5940. ISSN 01480227 doi: https://doi.org/10.1029/92JA02375 Available at https://centaur.reading.ac.uk/38824/

It is advisable to refer to the publisher's version if you intend to cite from the work. See Guidance on citing.

Published version at: http://dx.doi.org/10.1029/92JA02375

To link to this article DOI: http://dx.doi.org/10.1029/92JA02375

All outputs in CentAUR are protected by Intellectual Property Rights law, including copyright law. Copyright and IPR is retained by the creators or other copyright holders. Terms and conditions for use of this material are defined in the End User Agreement.

\section{www.reading.ac.uk/centaur}

\section{CentAUR}

Central Archive at the University of Reading

Reading's research outputs online 


\title{
On the Quasi-Periodic Nature of Magnetopause Flux Transfer Events
}

\author{
M. LOCKWOOD ${ }^{1}$ AND M. N. WILD \\ World Data Centre CI for Solar-Terrestrial Physics, Rutherford Appleton Laboratory, Chilton, Didcot, UK
}

\begin{abstract}
The recurrence rate of flux transfer events (FTEs) observed near the dayside magnetopause is discussed. A survey of magnetopause observations by the ISEE satellites shows that the distribution of the intervals between FTE signatures has a mode value of $3 \mathrm{~min}$, but is highly skewed, having upper and lower decile values of 1.5 $\mathrm{min}$ and $18.5 \mathrm{~min}$, respectively. The mean value is found to be $8 \mathrm{~min}$, consistent with previous surveys of magnetopause data. The recurrence of quasi-periodic events in the dayside auroral ionosphere is frequently used as evidence for an association with magnetopause FTEs, and the distribution of their repetition intervals should be matched to that presented here if such an association is to be confirmed. A survey of 1 year's $15-\mathrm{s}$ data on the interplanetary magnetic field (IMF) suggests that the derived distribution could arise from fluctuations in the IMF $B_{z}$ component, rather than from a natural oscillation frequency of the magnetosphere-ionosphere system.
\end{abstract}

\section{INTRODUCTION}

Flux transfer events (FTEs) are characteristic signatures in the magnetic field observed by satellites close to the dayside magnetopause. They were discovered in data from satellites close to the magnetopause by Russell and Elphic [1978, 1979] and, independently, by Haerendel et al. [1978]. Subsequently there have been a large number of case studies of these events [Paschmann et al., 1982; Saunders, 1983; Farrugia et al., 1987a, 1987b, 1988] and statistical surveys of their occurrence [Berchem and Russell, 1984; Rijnbeek et al., 1984; Daly et al., 1984; Southwood et al., 1986; Elphic, 1990; Lockwood, 1991].

There are several theoretical models aimed at explaining magnetopause FTE signatures, and Figure 1 shows arguably the most successful of those proposed to date, particularly in terms of explaining possible ground-based signatures (see review by Lockwood et al. [1990a]). This model is based on a suggestion by Saunders [1983] and Biernat et al. [1987]. Similar conclusions have resulted from a variety of subsequent work: Southwood et al. [1988] presented conceptual modelling; Scholer [1988] obtained similar results by 2-dimensional MHD numerical simulations; and Semenov et al. [1992] have presented an analytic derivation. All these studies invoke temporal variations in the reconnection rate, but not necessarily at a short $\left(\sim 1 R_{E}\right)$ neutral line, as described by Russell and Elphic and a large number of subsequent studies.

In order to understand this model, we note that all the evidence indicates that reconnection usually takes place quite close to the equatorial magnetopause (at the neutral line $X$ in Figure 1) when the interplanetary magnetic field (IMF) has a southward component. This evidence includes the resulting accelerated flows at the magnetopause [e.g., Gosling et al., 1990], the sense of the rotational field discontinuities defined by the "stress-balance test" [Paschmann, 1984], and the inferred source of the FTE signatures [Berchem and Russell, 1984; Rijnbeek et al., 1984, Daly et al.,

\footnotetext{
Also visiting at Imperial College, London.
}

Copyright 1993 by the American Geophysical Union.

Paper number 92JA-02375.

0148-0227/93/92JA-02375\$02.00
1984]. This reconnection converts closed field lines (such as that labeled c) to open field lines which thread the magnetopause (such as o). The time-dependent reconnection models predict that a variation in the reconnection rate produces a pair of "bubbles" of mixed magnetospheric and magnetosheath plasma. These are threaded by loops of the newly opened flux produced by the reconnection burst, as shown in Figure 1. The combined effect of the field curvature force (the so-called "magnetic tension") and of the magnetosheath flow moves these bubbles away from $\mathrm{X}$ and past spacecraft near the magnetopause (e.g., S1 and S2), causing the observed component of the magnetic field normal to the magnetopause, $B_{n}$, to vary. For the event shown in the northern hemisphere in Figure 1, this component points first away from, and then toward, the Earth as the bubble passes by. The same polarity of bipolar signature in $B_{n}$ is seen by spacecraft $S 1$ in the magnetosheath as by $S 2$, on the other side of the magnetopause, i.e., within the magnetosphere [Farrugia et al., 1987a,b; Lockwood, 1991]. Statistical surveys have shown that FTEs are observed almost exclusively when the IMF points southward, as measured in the undisturbed solar wind outside the bow shock by a satellite such as S3 in Figure 1 [Berchem and Russell, 1984], and are mainly, but not exclusively, observed when the exterior magnetosheath field points southward [Rijnbeek et al., 1984]. It should be noted that Berchem and Russell and Rijnbeek et al. also employed different classification schemes to identify FTEs.

Rijnbeek et al. [1984] reported the number of FTEs observed by the ISEE satellites during the intervals between the magnetopause crossing and the FTE furthest away from the boundary in the time series of the data. These intervals were typically of $30 \mathrm{~min}$ duration, and Rijnbeek et al. found that, on average, FTEs repeated at intervals of 7-9 $\mathrm{min}$. Subsequently, this result has often been interpreted as showing that FTEs are a quasi-periodic phenomenon, with a mean period of about 8 min. It is the purpose of this paper to discuss this interpretation (which, incidentally, Rijnbeek et al. did not themselves adopt).

Recently, there has been much interest in identifying the signature of FTEs in the ionosphere [see Southwood, 1987; Cowley et al., 1991]. One class of event, termed "dayside auroral breakup", is a particularly strong candidate [Sandholl et al., 1989]. These events are observed using optical instruments in the midday auroral region (point $I$ in figure 1 ) and are associated with bursts 


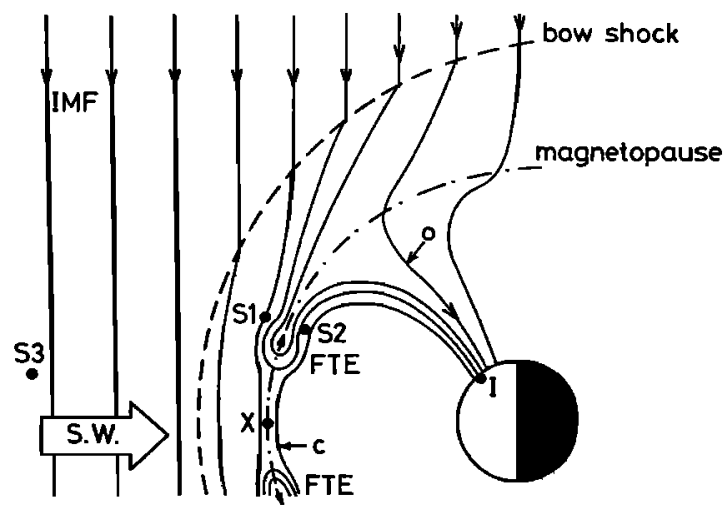

Fig. 1. Schematic illustration of the Southwood et al.Scholer model of the production of magnetopause FTEs, as observed by satellites close to the magnetopause, either in the magnetosphere (such as S2) or in the magnetosheath (S1). S3 marks a typical location of an IMF monitor, $X$ is the position of the reconnection $X$ line in the dayside magnetopanse, and $I$ is the ionospheric footprint of the newly opened field lines.

of plasma flow, as observed using the European Incoherent Scatter (EISCAT) radar [Lockwood et al., 1989]. The patterns of motion and plasma flow associated with these events are consistent with them being regions of newly opened flux. This is strong and direct evidence that they are indeed produced by bursts of magnetopause reconnection, as invoked by the time-dependent reconnection model to explain magnetopause FTE signatures. However, the optical observations of the noon aurora can only be made, in the northern hemisphere at least, from the Svalbard islands for a few weeks around winter solstice. In addition, clear skies, new moon, southward IMF, and simultaneous radar observations are required. In only one experiment has it been possible to observe these ionospheric signatures in association with magnetopause FTEs [Elphic et al., 1990] and the statistics on the occurrence of these events is, as yet, limited.

A limitation of the magnetopause observations is that we cannot determine the event dimension along the magnetopause, in the direction perpendicular to the event motion. However, this can be done from ground-based imaging and radar systems: because the ionospheric magnetic field $\left(B_{i}\right)$ is effectively constant, it follows that if we can estimate the area of the region of newly reconnected field lines in the ionosphere $\left(A_{i}\right)$, we know the magnetic flux reconnected during the event $\left(F=B_{i} A_{i}\right)$. Hence, if we can define the ionospheric signatures, we can evaluate the contribution of FTEs ( $F / \tau$, where $\tau$ is the event repetition period) to the average dayside reconnection voltage and to the consequent transfer of mass, energy, and momentum from the solar wind to the magnetosphere. Initial studies of this type indicate that bursts of enhanced reconnection (i.e., FTEs) can be major, and possibly the dominant, mechanism of this solar wind-magnetosphere coupling [Lockwood et al., 1990a,b].

In the absence of sufficient combined ionospheric and magnetopause observations, a method often used in attempts to identify ionospheric phenomena which may be associated with magnetopause FTE signatures, is to search for quasi-periodic events during southward IMF, with a mean repetition period close to that for the magnetopause signatures [e.g., Lockwood et al., 1989]. However, Rijnbeek et al. only quoted the average number of FTEs in certain periods for a selected data set. Inspection of various examples in the literature (cited above) shows magnetopause signatures classified as FTEs repeat with a range of periods, not just the average of $8 \mathrm{~min}$. Hence it is important to know the distribution of the intervals between magnetopause
FTEs, to allow comparison with the corresponding distribution for any one type of ionospheric signature, if an association is to be confirmed. This paper studies that distribution for a selected set of magnetopause FTE signatures observed by the ISEE spacecraft.

It remains unclear if the rate of FTE occurrence reflects a natural oscillation period of the magnetosphere-ionosphere system under the influence of steady interplanetary conditions and/or is caused by variations in the solar wind or IMF impinging upon the magnetosphere. It is known that the reconnection rate is strongly influenced by the magnetic shear across the dayside magnetopause and hence by the north-south component (in GSM coordinates) of the IMF, $B_{z}$ (see reviews by Cowley [1984] and Reiff and Luhmann, [1986]). In this paper, we also investigate the variability of the IMF $B_{2}$ component as a possible cause of the occurrence of FTEs.

\section{ANALYSIS}

In this paper, we investigate the repetition interval of magnetopause FTEs and the variability of the IMF $B_{z}$ component using statistical surveys of two data sets.

\subsection{Magnetopause Data}

The magnetopause data employed here were obtained by the magnetometers on board the ISEE (International Sun-Earth Explorer) 1 and ISEE 2 spacecraft. These data were accrued in the periods October 24, 1977 - January 2, 1978 and July 5, 1978 December 20, 1978 and a pass on September 11, 1979. This is the same data set as employed by Rijnbeek et al. [1984] in their statistical survey. Typically, the ISEE spacecraft were close enough to the magnetopause to observe the FTE signatures for periods of 1 hour about each magnetopause crossing. A total of 172 magnetopause passes are included in this survey, which only includes data for magnetic local times of 06-18 hours.

\subsection{IMF Data}

The IMF data were all recorded by the magnetometer on the IMP8 spacecraft when in the solar wind, upstream of the Earth's bow shock.

The ISEE data described above were all taken around solar maximum, and we wished to compare with IMF data for the same phase of the solar cycle. Very few IMF data of 15.339-s resolution (the highest obtained by IMP 8) are available to us for the periods of the ISEE observations discussed above. However, a considerable number of such data are stored in a relational data base in the World Data Centre $\mathrm{Cl}$ at Rutherford Appleton Laboratory for the subsequent solar maximum. We here employ IMF data observed in the periods December 26, 1987 to May 31, 1988, April 8, 1989 to August 28, 1989 and January 1, 1990 to February 19, 1990. In total, these periods cover 349 days and include 1,266,686 separate 15.339-s IMF observations. This is a data availability of $64.5 \%$ over the period considered of almost 1 year.

\subsection{The Distribution of Inter-FTE Intervals}

The magnetopause data were sorted, depending on whether the satellite was in the magnetosheath ( $\mathrm{S} 1$ in Figure 1) or within the magnetosphere (S2). The FTEs were defined using the criterion employed by Rijnbeek et al. [1984]. However, we lowered the arbitrary minimum duration of 1 min employed by Rijnbeek et al. to $30 \mathrm{~s}$. This was because we found that this cut off tended to eliminate the shorter inter-FTE intervals. This finding is consistent 
with the survey of ISEE and AMPTE (Active Magnetospheric Particle Tracer Exploreres) FTE observations presented by Elphic [1990]. Relaxing this limit added 201 short-period FTEs to the catalogue of Rijnbeek et al. However, the majority of these extra events were observed when the spacecraft were very close to the magnetopause and the requirement that successive events were on the same side of the boundary means that they do not greatly influence the inter-FTE interval statistics. Nevertheless, their inclusion allows the study of the shorter FTE intervals.

The center of an FTE was defined as where the estimated boundary normal field passed through zero. This definition means that enrors are introduced by the normal direction determination: however, systematic errors do not influence the inter-FTE interval, and random errors should average to zero with sufficient numbers of cases. The lengths of the intervals between the centers of successive FTE signatures, $\tau$, were then measured. This was done for magnetosheath and magnetosphere data sets separately. The distribution of $\tau$ values was not substantially different for FTEs observed within the magnetosphere from that of FTEs observed within the magnetosheath, and here we aggregate the two together. However, note that treating magnetosheath and magnetosphere data separately excludes intervals between an FTE being observed on one side of the boundary and a second FTE being observed on the other side of the boundary later in the pass. This is important because the characteristic FTE signature may not be observed if the satellite is very close to the magnetopause [Farrugia, 1989] and hence the time between two such events could be the sum of several inter-FTE intervals. The failure to detect an FTE very close to the boundary is because the timedependent reconnection models predict loops of newly opened field lines giving field lines which bulge away from the current layer to either side. However, at the center of the current layer, the only signature would be the boundary normal field threading the magnetopause (which cannot be determined because the boundary orientation is not known with sufficient accuracy). The signature we should detect at this location is the presence of accelerated ion flows, produced as particles cross the rotational discontinuity in the field [e.g., Gosling et al., 1990]. However, these particles tell us only of the existence of ongoing reconnection; they do not tell us about the rate of reconnection. Hence the term "quasi-steady" reconnection is often misused: the detection of accelerated flows over a prolonged period tells us that there is "quasi-continuous" reconnection, not that it is steady in rate.

A total of 621 FTEs were identified, which yielded $N=341$ inter-FTE intervals with the spacecraft remaining to one side or other of the magnetopause. Of these, 217 were with the satellite in the magnetosheath, and 124 were with the satellite in the boundary layer, inside the magnetosphere.

We then evaluated $n$, the numbers of cases for which $\tau$ had values in 1-min bins. Figure 2 shows the fraction of the cases $(n / N)$ as a function of the inter-FTE interval $\tau$ from the ISEE data set described above. The mean value of this distribution is $\langle\tau\rangle=$ $8 \mathrm{~min}$, very similar to the mean recurrence time found by Rijnbeek et al. [1984]. However, the distribution is highly skewed, with the lower decile being just $1.5 \mathrm{~min}$ and the upper decile being $18.5 \mathrm{~min}$. The mode value of the distribution is $3 \mathrm{~min}$. We note that this form of distribution is also inherent in the scatter plot of a smaller set of FTE signatures presented by Elphic [1990]. It can be seen that the mean value of the intervals $(8 \mathrm{~min})$ is not marked by any significant peak in the distribution.

Matching the whole of this distribution gives us a potentially more stringent test of any putative ionospheric FTE signature than just checking that the mean repetition period is $8 \mathrm{~min}$.

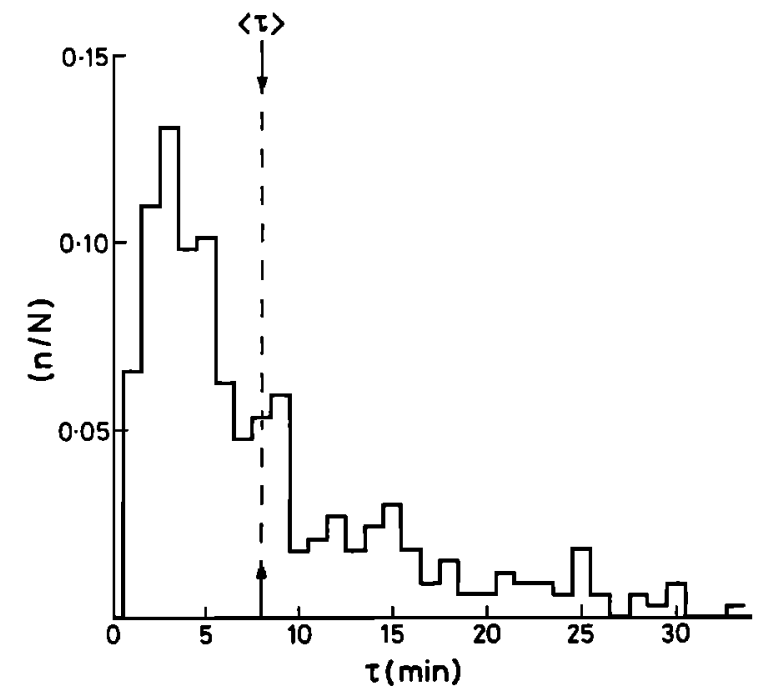

Fig. 2. The distribution of inter-FTE intervals from the ISEE magnetopause data. The number of cases, $n$, for each 1 -min bin of the interval length, $\tau$, is shown, normalized by the total number, $N=341$.

\subsection{Variability of the IMF $B_{z}$ Component}

If averaged over several substorm cycles, the dayside reconnection rate equals the voltage appearing across the ionospheric polar cap, plus only a very small contribution from "viscous like" interactions (see discussion by Lockwood and Cowley [1992]). Statistical surveys show that this voltage depends upon the IMF $B_{z}$ component, being small when the IMF is northward and increasing with increasing magnitude of southward IMF (see reviews by Cowley [1984] and Reiff and Luhmann [1986]). Hence the average dayside reconnection rate increases with the magnetic shear across the dayside magnetopause and the magnitude of the IMF $\mathbf{B}_{\mathbf{z}}$ component, when it is negative. This average behavior also appears to apply on somewhat shorter time scales (about $5 \mathrm{~min}$ ), explaining the rapid response of dayside ionospheric flows to the appearance of increased magnetic shear across the magnetopause [Etemadi et al., 1988; Todd et al., 1988; Lockwood et al., 1989; Lockwood and Cowley, 1992]. The FTE model demonstrated in figure 1 invokes increases in reconnection rate as the cause of magnetopause FTE signatures. The reasons for such increases in the reconnection rate are not specified (e.g., Scholer [1988] imposes a pulse of anomalous resistivity in his simulations, Semenov et al. [1992] impose a pulse of tangential electric field). The possibility investigated here is that the reconnection rate variations simply reflect variations in the IMF $B_{\mathbf{z}}$ component.

As a first attempt to investigate whether the distribution of FTE repetition periods might reflect some variability in the IMF, an analysis of the distributions of periods when the IMF $B_{2}$ remained either above or below certain thresholds was carried out.

The IMF data were transformed into the GSM coordinate system. The periods for which the hourly average of the IMF was southward (i.e., $\left\langle\mathrm{B}_{\mathbf{z}}\right\rangle<0$ ) were selected. This selection was carried out because FTEs occur almost exclusively when the mean IMF is southward [Berchem and Russell, 1984]: it reduces the size of the data set by a factor of almost exactly 2 because the distribution of the hourly averages of $\mathrm{B}_{\mathrm{z}}$ is almost exactly symmetrical about zero. The times of all transitions of the IMF across a threshold value $B_{2 T}$ were then defined in the 15.339-s resolution IMF data, i.e., transitions from $B_{z}>B_{z T}$ to $B_{z}<B_{2 T}$ were identified, as were all the transitions in the reverse direction 

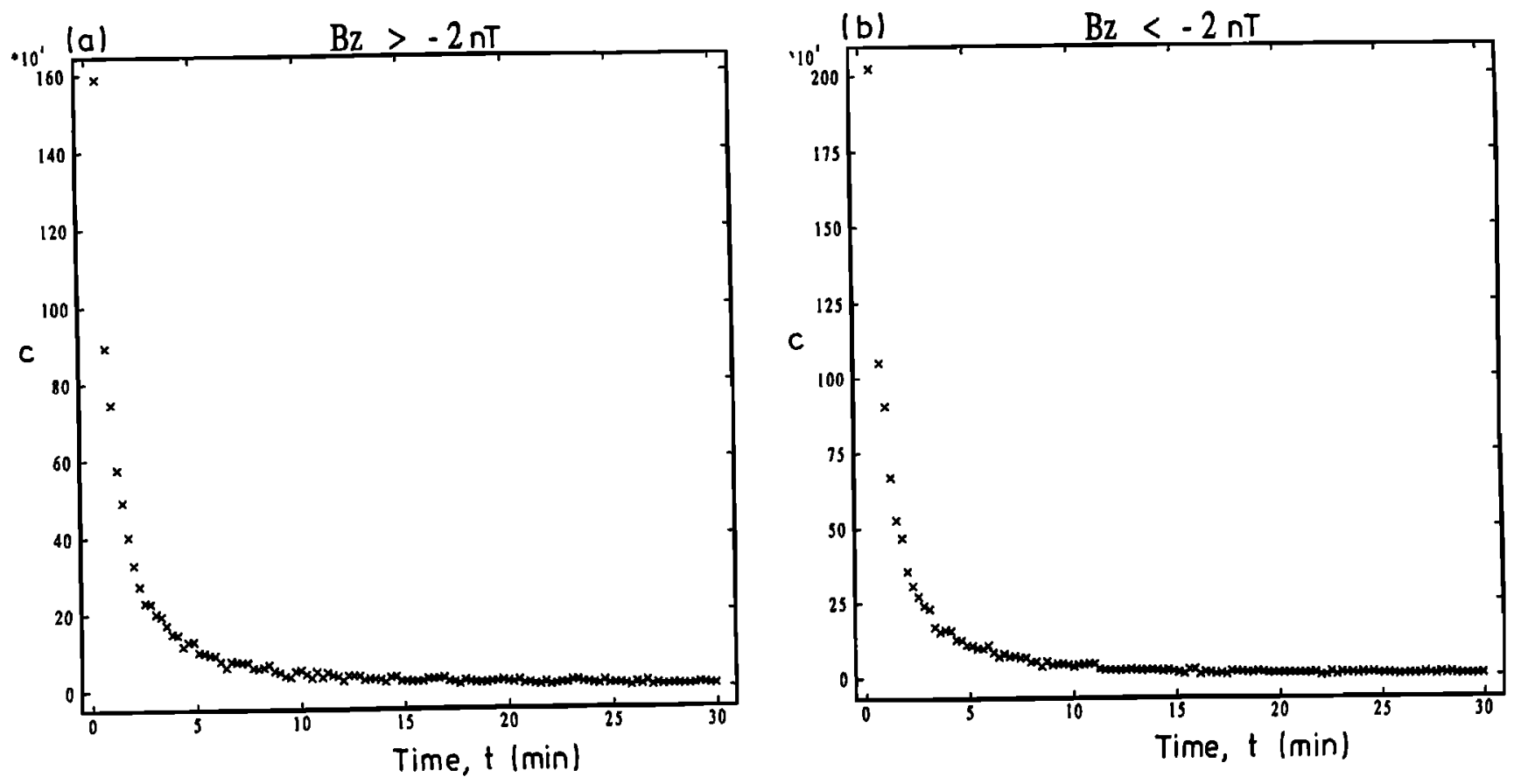

Fig. 3. (a) The distribution of intervals when the IMF $B_{z}$ is continuously (i.e., $\alpha=1$; see text) greater than a threshold value $B_{2 T}$ $=-2$ nT. (b) The corresponding distribution for periods when $B_{2}$ is less than this threshold.

across this $B_{x r}$ threshold. From these transition times, the duration of each period when the IMF $B_{2}$ was greater than this threshold was evaluated. Likewise, the durations of periods when $B_{2}$ was less than $B_{2 T}$ were also evaluated. The results presented here consider such intervals to be ended by a single 15.339-s sample having a value on the other side of the threshold. The analysis was repeated with a requirement that $\alpha$ successive 15.339-s samples on the other side of the threshold were needed to terminate an interval, i.e., that $(\alpha-1)$ such samples were not considered significant. In addition to the $\alpha=1$ case presented here, the analysis was repeated for $\alpha=2, \alpha=3$, and $\alpha=4$. The results were found to be largely independent of $\alpha$, for the range of periods which are of concern here, which is roughly $2-30 \mathrm{~min}$.

Figure 3a shows the distribution of interval lengths for which the IMF $B_{2}$ was greater than $B_{2 T}=-2 n T$ but the hourly average of $B_{k}$ was negative. It can be seen that the number of cases, $c$, in each range between $t$ and $(t+15.339 s)$ increases monotonically with decreasing period length, $t$, at all values. No significant change in the shape of the distribution was found if the threshold value, $B_{2 T}$, was altered, but the total numbers of the counts differed. Figure $3 \mathrm{~b}$ shows the corresponding distribution for periods when the IMF $B_{2}$ was less than the $B_{2 T}=-2 n T$ threshold.

\section{Discussion}

Figure 4 compares the two distributions shown in Figures 2 and 3a. In this plot, the number of inter-FTE intervals, $n$, for each $1-$ min bin is plotted as the solid line. The crosses mark the counts, c, for the IMF intervals in 15.339-s windows, divided by an arbitrary scaling factor of 3.5, which minimizes the squares of the differences. The scaling factor largely reflects the different total intervals of the two data sets. It can be seen that the distributions are very similar in form for periods at and above $3 \mathrm{~min}$. The possible significance of this is discussed in this section.

In comparing these two distributions, a number of factors concerning the detection of FTEs must be considered. First, if the interval between FTEs were too small, the events would not be classed as FTEs, even with the shorter duration criterion. Close to the magnetopause, extended variations in the reconnection rate with periods of less than about 1 min would almost certainly give signatures classed as "B activity", rather than as a series of FTE signatures with very small inter-FTE intervals. Two isolated FTEs, with a short period between them, could also be classified as a single event. Another factor is that many of the FTEs included in

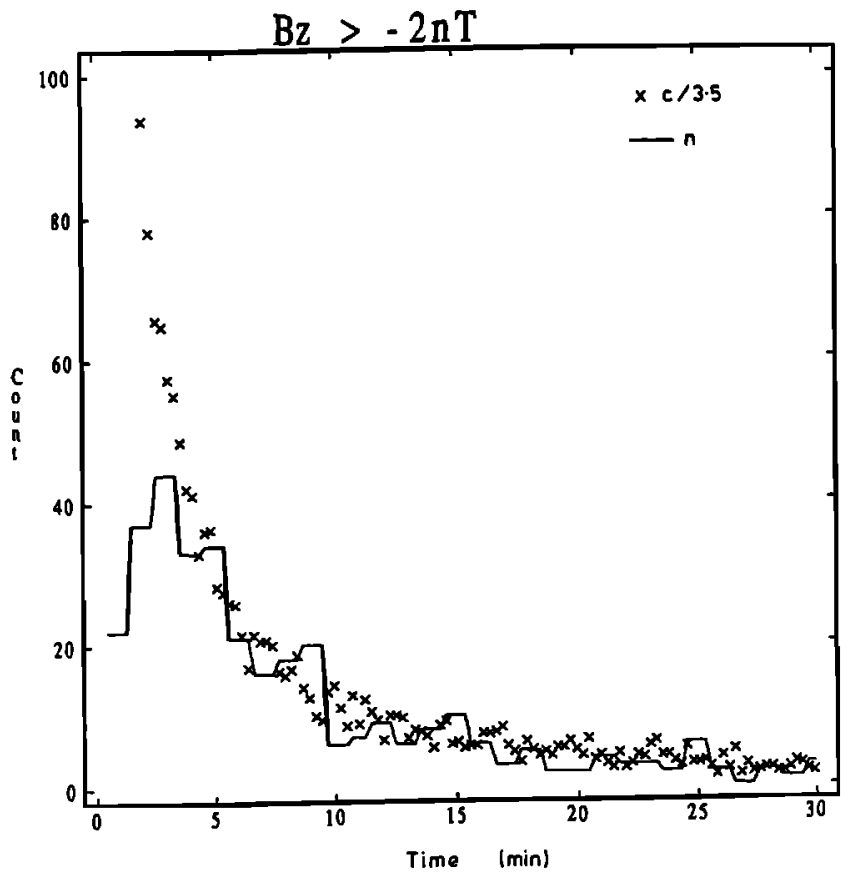

Fig. 4. The distributions shown in Figures 2 and 3a superposed, shown as a solid line and crosses, respectively. The axis labeled "count" gives the number of cases, $n$, of inter-FTE intervals in 1 -min bins, and the number of periods of IMF $B_{z}>B_{z r}$ in 15.339-s bins, divided by a scaling factor of 3.5. 
the survey were detected at more than about $1 R_{E}$ from the magnetopause. In such cases, the satellite does not detect the bipolar signature in the boundary normal field $B_{n}$ because it has intersected the loops of newly opened field lines within the FTE bubble. However, a bipolar $B_{n}$ signature is still observed as the satellite moves through the regions in which the ambient magnetosheath or magnetospheric field is draped over the FTE bubble [Farrugia et al., 1987a]. Rapid variations in the reconnection rate would give multiple bubble like structures which were very close together [Farrugia, 1989], and the structure would be increasingly smoothed out with increasing distance from the magnetopause. Hence we would not resolve all the FTEs, and we should not expect the FTE distribution to reflect the very rapid variations in the IMF $B_{2}$ component. Hence there are a number of reasons for the divergence of the two curves at low periods, as shown by Figure 4.

In addition, we note that the very rapid variation in IMF $B_{2}$ may not propagate through the bow shock and across the magnetosheath to be reflected in variations of the southward magnetosheath field at the nose of the magnetosphere. If the magnetosheath does act to filter out the higher frequency variations in this way, that too would contribute to the difference between the two curves in Figure 4.

Hence we can state the distributions are, at least, not inconsistent with the simple hypothesis that when the IMF $B_{z}$ is less than a certain threshold, the reconnection rate is larger and an FTE is produced. When $B_{2}$ is greater than this threshold, reconnection may cease or may continue, but at a lower and more steady rate, and these intervals account for the inter-FTE periods. Note, however, that because virtually the same shape distribution was obtained for different thresholds $\left(B_{\mathrm{zT}}\right.$ of $-4 \mathrm{nT}$ and $-6 \mathrm{nT}$ were employed as well as the $-2 \mathrm{nT}$ shown in Figure 3 ), this analysis does not tell us that there really is such a threshold, nor what value it has.

The distribution of the durations of periods of IMF $B_{2}$ consistently less than $-2 \mathrm{nT}$ (Figure $3 \mathrm{~b}$ ) shows a very similar form to figure 3a. If we take the simple hypothesis that $\mathrm{B}_{2}$ below the $-2 \mathrm{nT}$ threshold produces an FTE, then this distribution should reflect the distribution of FTE durations. The results presented by Elphic [1990] are consistent with this concept.

Lastly, we note that in this paper we have only considered the distribution of intervals for variations in the $\mathrm{B}_{2}$ component in the IMF, because of previous studies showing the importance of this component for the reconnection rate for longer (typically 1-hour) time scales [Cowley, 1984, Reiff and Luhmann, 1986]. The $B_{x}$ and $B_{y}$ components of the IMF show similar distributions. In addition, there are similar spectra of variations in solar wind speed, density, and dynamic pressure. Hence the results presented do not prove that the reconnection rate is simply modulated by the value of the southward component of the IMF. However, the results do indicate that FTEs may simply reflect part of a spectrum of reconnection rate variations, which could simply reflect changes in the interplanetary medium.

\section{ConClusions}

The distribution of recurrence periods of magnetopause FTEs is highly skewed, with a mode value of $3 \mathrm{~min}$, a lower decile of $1.5 \mathrm{~min}$ and an upper decile of $18.5 \mathrm{~min}$. There is no significant peak in the distribution at the average value of $8 \mathrm{~min}$, suggesting that FTEs are not really quasi-periodic, but rather they are part of a wider spectrum of reconnection rate variations.

This distribution must be matched to that of any repetitive variations in the dayside auroral ionosphere if that phenomenon is to be associated with the magnetopause FTE signatures, although the various detection methods and thresholds will cause differences.

The shape of the distribution does not suggest that the $8 \mathrm{~min}$ average periodicity of FTEs reflects a natural oscillation period of the magnetosphere-ionosphere system. Using a simple hypothesis, namely that IMF $B_{z}$ less than a certain threshold causes an FTE, and IMF consistently above this threshold results in the inter-FTE interval, we see that the statistics of IMF variability are not inconsistent with the variations in reconnection rate being caused by variations in the IMF $B_{2}$ component.

This suggestion is very difficult to confirm using simultaneous data from the upstream solar wind and at the dayside magnetopause, because prediction of the propagation delay from the IMF monitor (S3 in Figure 1) to the $X$ line (X), and the subsequent travel time of the FTE from the $X$ line to the magnetopause satellite ( $\mathrm{S} 1$ or $\mathrm{S} 2$ ) is open to considerable uncertainties. Not least of these is because we do not know exactly where the $\mathrm{X}$ line is situated. Other uncertainties arise from the orientation of the IMF variations in interplanetary space and the position of the IMF monitor, the variability of the position of the bow shock, and the variation of the plasma speed along the magnetopause. Similar, but less severe limitations would afflict a similar study using magnetosheath data. The problem in this latter case is that the passage of the FTE may locally mask any signature in the magnetosheath $\mathrm{B}_{\mathrm{L}}$ component.

Acknowledgments. We wish to thank R. P. Lepping for provision of the IMP 8 data and C. T. Russell for provision of the ISEE data. We also thank M. A. Saunders and R. P. Rijnbeek for their help and S. W. H. Cowley for many valuable discussions.

The Editor thanks the referees for their assistance in evaluating this paper.

\section{REFERENCES}

Berchem, J., and C. T. Russell, Flux transfer events on the magnetopause: Spatial distribution and controlling factors, J. Geophys. Res., 89. 6689-6703, 1984.

Biemat, H. K., M. F. Heyn and V. S. Semenov, Unsteady Petschekreconnection, J. Geophys. Res., 92, 3392-3396, 1987.

Cowley, S. W. H., Solar wind control of magnetospheric convection, in Achievements of the Intemational Magnetospheric Study, IMS, Eur. Space Agency Spec. Publ., ESA SP.217, 483-494 1984.

Cowley, S. W. H., M. P. Freeman, M. Lockwood, and M. F. Smith, The ionospheric signature of flux transfer events, in Proceedings of the CLUSTER workshop on Longyearbyen, Eur. Space Agency Spec. Publ., ESA SP-330, 105-112, 1991.

Daly, P. W., M. A. Saunders, R. P. Rijnbeek, N. Sckopke, and C. T.Russell, The distribution of reconnection geometry in flux transfer events using energetic ion, plasma and magnetic data, J. Geophys. Res., 89, 3843-3851, 1984.

Elphic, R. C., Observations of flux transfer events: Are FTEs flux ropes, islands, or surface waves?, in Physics of Magnetic Flux Ropes, Geophys. Monogr. Ser., vol. 58, edited by C. T. Russell, E. R. Priest, and L. C. Lee, Pp. 455-472, AGU, Washington, D. C., 1990.

Elphic, R. C., M. Lockwood, S. W. H. Cowley, and P. E. Sandholt, Signatures of flux transfer events at the dayside magnetopause and in the ionosphere: Combined ISEE, EISCAT and optical observations, Geophys. Res. Lett., 17, 2241-2244, 1990.

Etemadi, A., S. W. H. Cowley, M. Lockwood, B. J. I. Bromage, D. M. Willis, and $H$. Lühr, The dependence of high-latitude dayside ionospheric flows on the north-south component of the IMF: A high time resolution correlation analysis using EISCAT "POLAR" and AMPTE UKS and IRM data, Planet. Space Sci., 36, 471-498, 1988.

Farrugia, C. J., Observations of solar-wind-magnetosphere coupling at the Earth's magnetopause, Philos. Trans. R. Soc. London, Ser. A, 328, 57 $77,1989$. 
Farrugia, C. J., R. C. Elphic, D. J. Soutbwood, and S. W. H. Cowley, Field and flow perturbations outside the reconnected field line region in flux transfer events: Theory, Planet. Space Sci., 35, 227-240, 1987a.

Farrugia, C. J., D. J. Southwood, S. W. H. Cowley, R. P. Rijnbeek, and P. W. Daly, Two-regime flux transfer events, Planet. Space Sci., 35, 737-746, 1987b.

Farrugia, C. J., R. P. Rijnbeek, M. A. Saunders, D. J. Southwood, D.J. Rodgers, M. F. Smith, C. P. Chaloner, D. S. Hall, P. J. Christiansen, and L. J. C. Woolliscroft, A multi-instrument study of flux transfer event structure, J. Geophys. Res., 93, 14465-14477, 1988.

Gosling, J. T., M. F. Thomsen, S. J. Bame, R. C. Elphic, and C. T. Russell, Plasma flow reversals at the dayside magnetopause and the origin of asymmetric polar cap convection, J. Geophys. Res., 95, 8073-8084, 1990.

Haerendel, G., G. Paschmann, N. Sckopke, H. Rosenbauer, and P. C. Hedgecock, The frontside boundary layer of the magnetopause and the problem of reconnection, J. Geophys. Res., 83, 3195-3216, 1978.

Lockwood, M. Flux transfer events at the dayside magnetopause: Transient reconnection or magnetosheath pressure pulses?, J. Geophys. Res., 96, 5497-5509, 1991.

Lockwood, M., and S. W. H. Cowley, Ionospheric convection and the substorm cycle, in Substorms 1, Eur. Space Agency Spec. Publ., ESA SP-335, 99-109, 1992.

Lockwood, M., P. E. Sandholt, S. W. H. Cowley and T. Oguti, Interplanetary magnetic field control of dayside auroral activity and the transfer of momentum across the dayside magnetopause, Planet. Space Sci., 37, 1347-1365, 1989.

Lockwood, M., S. W. H. Cowley, and P. E. Sandholt, Transient reconnection - the search for ionospheric signatures, Eos, Trans. AGU, 71 (20), 709-720, 1990a.

Lockwood, M., S. W. H. Cowley, P. E. Sandholt, and R. P. Lepping, The ionospheric signatures of flux transfer events and solar wind dynamic pressure changes, J. Geophys. Res., 95, 17113-17135, 1990b.

Paschmann, G., Plasma and Particle observations at the magnetopause: implications for reconnection, in Magnetic Reconnection in Space and Laboratory Plasmas, Geophys. Monogr. Ser., vol. 30, edited by E.W. Hones, Jr., pp. 114-123, AGU, Washington D. C., 1984.

Paschmann, G., G. Haerendel, I. Papamastorakis, N. Sckopke, S. J. Bame, J. T. Gosling, and C.T. Russell, Plasma and magnetic field characteristics of magnetic flux transfer events, J. Geophys. Res., 87, 2159-2168, 1982.
Reiff, P. H., and J. G. Luhmann, Solar wind control of the polar cap voltage, in Solar Wind-Magnetosphere Coupling, edited by Y. Kamide and J.A. Slavin, Pp. 453-472, Terra Scientific, Tokyo, 1986.

Rijnbeek, R. P., S. W. H. Cowley, D. J. Southwood, and C. T. Russell, A survey of dayside flux transfer events observed by the ISEE 1 and 2 magnetometers, J. Geophys. Res., 89, 786-800, 1984.

Russell, C. T., and R. C. Elphic, Initial ISEE magnetometer results: Magnetopause observations, Space Sci. Rev., 22, 681-715, 1978.

Russell, C. T., and R. C. Elphic, ISEE observations of flux transfer events at the dayside magnetopause, Geophys. Res. Lett., 6, 33-36, 1979.

Sandholt, P. E., B. Lybekk, A. Egeland, R. Nakamura, and T. Oguti, Midday auroral breakup, J. Geomag. Geoelectr., 41, 371-387, 1989.

Saunders, M. A., Recent ISEE observations of the magnetopause and low-latitude boundary layer: A review, J. Geophys., 52, 190-198, 1983.

Scholer, M., Magnetic flux transfer at the magnetopause based on single X-line bursty reconnection, Geophys. Res. Lett., 15, 291-294, 1988.

Semenov, V. S., I. V. Kubyshkin, V. V. Lebedeva, M. V. Sidneva, H. K. Biemat, M. F. Heyn, B. P. Besser and R. P. Rijnbeek, Timedependent localized reconnection of skewed magnetic fields, $J$. Geophys. Res., 97, 4251-4263, 1992.

Southwood, D. J., The ionospheric signature of flux transfer events, $J$. Geophys. Res., 92, 3207-3213, 1987.

Southwood, D. J., M. A. Saunders, M. W. Dunlop, W. A. C. MierJedrzejowicz, and R. P. Rijnbeek, A survey of flux transfer events recorded by UKS spacecraft magnetometer, Planet. Space Sci., 34, 1349-1359, 1986.

Southwood, D. J., C. J. Farrugia, and M. A. Saunders, What are flux transfer events?, Planet. Space Sci., 36, 503-508, 1988.

Todd, H., S. W. H. Cowley, A. Etemadi, B. J. I. Bromage, M. Lockwood, D. M. Willis and H. Luihr, Flow in the high-latitude ionosphere: measurements at 15-second resolution made using the EISCAT "POLAR" experiment, J. Atmos. Terr. Phys., 50, 423-446, 1988.

M. Lockwood and M. N. Wild, World Data Centre Cl for SolarTerrestrial Physics, Rutherford Appleton Laboratory, Space Science Department, Chilton, Didcot, Oxon. OX11 0QX, England, U.K.

(Received April 9, 1992;

revised September 28, 1992;

accepted September 28, 1992.) 